\title{
A Model Proposal to Address Relationships Between Epistemic Practices and Socioscientific Issues in Science Education
}

\author{
(D) Tatiana Costa Ramos, Paula Cristina Cardoso Mendonça
}

\begin{abstract}
Keywords Abstract In this paper, we present a model that relates epistemic Epistemic practices and socio-scientific issues (SSI) in science education. In order objectives; to develop it, we establish interweavings between norms, practices, Informal reasoning; epistemic objectives, epistemic cognition, informal reasoning, Epistemic epistemic practices and justified positioning. We suggest that epistemic cognition; cognition is the link between reasoning and epistemic practices. We Social norms. present three epistemic goals that should guide work with epistemic practices when solving a SSI: recognising and using multiple lines of reasoning when solving the SSI, construction and evaluation of holistic arguments aiming to understand the multiple dimensions of the SSI and the development of sceptical investigations to resolve the SSI. The stated objectives contribute to the critical assessment and resolution of the SSI. We believe that for the construction of social norms in teaching environments with SSI, it should be considered that these questions do not require a "single" answer and, therefore, a space for reflection, awareness and justification of the different perspectives on the question must be allowed. The relationships established in this article contribute to research that aims to develop and analyse epistemic practices "in situ" in teaching contexts with SSI. In addition, they have the potential to provide support to teachers who wish to favour the occurrence of epistemic practices in a SSI approach.
\end{abstract}

\section{Introduction}

Published on 20th August 2021

A desirable target for Science Education consists of the students' involvement with the epistemic goals of Science (Jiménez-Aleixandre \& Crujeiras, 2017; Kelly, 2008; Kelly \& Duschl, 2002). As proposed by Duschl (2008), Science Education should establish a balance between conceptual and epistemic cognition within subject work, from a perspective of social learning. Epistemic goals of Science are linked to the sphere of 'how we know what we know'; in other words, how scientific knowledge is produced and legitimated within scientific communities (Jiménez-Aleixandre \& Crujeiras, 2017; Duschl, 2008). Within the context of Science teaching, the emphasis on these goals 
may contribute through the justification of statements of knowledge in the classroom and through students' understanding of scientific knowledge as a human construction of a social nature; produced in scientific communities based on social practice and standardised actions, which are recognised and internalised within its members, and which guide scientific work (Kelly, 2008).

In this way, over the last few years, researchers of the area of Science Education (such as Berland et al., 2015; Erduran, 2015; Jiménez-Aleixandre \& Crujeiras, 2017; Osborne, 2014; Stroupe, 2014) highlight the work with Science practice in the Science classroom. This is justified through the learning of conceptual, epistemic and social goals based on engagement of the students with such goals.

Work with Science practices in the classroom shall have the main aim of construction of a teaching environment in which the students' knowledge of the world and aspects of scientific work shall be exploited in an authentic manner, which means keeping a connection with what occurs in Science, but in a way that is significant for them (González-Howard \& McNeill, 2019; Pierson et al., 2019; Stroupe, 2015).

In this regard, some research studies (Christodoulou \& Osborne, 2014; Kelly \& Licona, 2018; Lidar et al., 2005; Sandoval, 2005; Sasseron \& Duschl, 2016; Silva, 2015) have a focus on epistemic practices which emerge within the process for the teaching and learning of science. Epistemic practices are defined as the ways in which individual people, as members of a community, Interact seeking to produce, appraise, communicate and legitimate knowledge (Kelly, 2008).

Epistemic practices of Science within Science Education favour the involvement of students in the processes of production, assessment, communication and legitimation of knowledge that has a relationship with construction in Science. At the same time, they favour understanding of how the social processes of Science justify our beliefs in models, laws, theories, and scientific concepts (Kelly \& Duschl, 2002).

We also consider that the perspective of learning based on the practice community, in which knowledge and learning are constituent elements of individuals' participation in social practices within their communities (Lave \& Wenger, 1991) could help to envisage how epistemic practices came about and how they get established within contexts of teaching with a SSI approach. Thinking based on this perspective, we must consider that, according to the approach to teaching (for example, with socioscientific questions (SSI) or through an investigative approach), different objectives, practices, standards, identities, and values are shared by members of the community (Kelly \& Licona, 2018; Lave, 1996; Sadler, 2009).

Therefore, it is no easy task to Project teaching environments in which the epistemic practices of Science are given priority, which also requires a look at the particularities of the approaches to teaching. Considering that (i) research into epistemic practices are focused on the investigative approach (Motta et al., 2018; Sasseron \& Duschl, 2016; Silva, 2015) and (ii) the approach based on teaching with SSI differs from the investigative approach in relation to the goals, knowledge and reasoning involved; in the present article we shall 
make some studies of the particularities of the standards that need to be constructed in the classroom community with SSI, and we also connect the reasoning process involved in the solution of an SSI and epistemic practices. We prepare a model that addresses relationships between communities of practice, standards and social practices, epistemic cognition, reasoning, and epistemic goals and practices, to be able to contribute to in situ research studies on epistemic practices in approaches to teaching with SSI.

Our goals are justified especially due to the absence of academic works that connect epistemic practices and SSI. We now present greater details about the gaps in academic literature and about SSI within Science Education, as also the potential of this approach, which justifies our effort in the establishment of theoretical relationships.

\section{Situating research in specialised literature on Science Education}

When approached within the teaching process, SSI are drawn up based on problems or controversial situations of a social ilk, and whose possible solutions require an articulation between scientific knowledge from different subject areas, as also ethical, political and economic considerations. For example, public health problems in the current case, regarding the use of hydroxychloroquine as treatment for Covid-19, and vaccination as a more general form of treatment) or current social and environmental problems (such as global warming and the greenhouse effect; production of foodstuffs using pesticides versus agroecological production; extinction of bees) are examples of issues for development of SSI within Science Education (Conrado \& Nunes-Neto, 2018; Sadler et al., 2017; Zeidler et al., 2005).

Due to the controversial nature of such questions, and the possibility of them accepting many different solutions, they require the students making a decision about which position should be taken up. This means that, within Science Teaching, we should lead the students to look at these problems from many different angles, and also present them with a wide range of resources for the solution of SSI, so as to expand their view of problems under discussion, so that the solution of SSI may be critical and well-justified (Conrado \& Nunes-Neto, 2018; Dionor et al., 2020; Sadler, 2009). In other words, we need to avoid simplistic approaches, for example those where there only the spread of the view that increased development of scientific and technological knowledge contribute to greater well-being of the nation, without considering social inequalities. As teachers, on promoting SSI, we want students to be able to make queries: 'Why are things like this? Why can't they be different?', and thus enable thought rather than accommodation and indoctrination.

In this regard, one of the main goals of teaching with SSI is the promotion of scientific literacy - which is the qualification of people who are able to deal with issues of scientific vase, starting out from an active and critical role in decision-making and positioning within society (Hudson, 2018). Together with this, the teaching approach using SSI makes it possible to create virtue and character in the students based on moral judgements, which is part of a thought over implicit and/or explicit ethical components, 
with regard to the problems (Zeidler et al., 2009; Zeidler et al., 2005). Moral judgement is opportunised because the SSI bring out ethical and moral thoughts about what the 'correct' decision would be, and what we' should' do. The establishment and choice of the right answer (what we should do) raises issues and concerns about morality (what actions are right, and which are wrong) and ethics (the reasons and justifications to consider such actions as either right or wrong) (Hodson, 2018). Here we should mention that this is not a question of seeking the answer that is 'right' based on a standard determined in advance, because the issue of 'right' and 'wrong' shall be linked to the ability to raise queries about the order currently in effect, critical analysis of hegemonic cultural standards, and also the possibility of envisaging actions and scenarios that surpass immediate answers given without any thought and without common sense, with regard to the enforced reality (Nunes-Neto \& Conrado, 2021).

The approach to teaching with SSI also has the potential of enabling work with epistemology of Science in the classroom (Sadler et al., 2007; Zeidler et al., 2019; Zeidler et al., 2009). The SSI allow the contextualisation of knowledge about Science, on exploiting the relationships between technology, society, and the nature of the scientific work. In fact, Zeidler and collaborators (2009) observed that the experience of high school students with SSI over one academic year allowed the development of viewpoints about science investigation, in a contextualised manner. However, turning to the implications of the research, the authors then argued that, even though the teachers promote development of coherent viewpoints about Science in the students, it is still more relevant for the work with aspects of Science in the classroom to go beyond the mere formation of viewpoints and beliefs, so that the students may get involved in other situations related to scientific activity. Other research studies about epistemologies in Science Education (Kelly, 2008; Kelly \& Duschl, 2002; Mendonça, 2020; Lidar et al., 2005; Sandoval, 2005) also consider that epistemology of Science in the classroom should be exploited using a perspective that considers the appropriation of ideas and Science practices by the students. This stresses the need to investigate the relations between scientific activities, on the one hand, with the process of reasoning during the solution of an SSI, so as to favour the work with the epistemic practices of Science, in a way that the students may develop, criticise and use such practices for the solution of such questions (Berland et al., 2015; Kelly \& Duschl, 2002).

Together with this, considering that the mobilisation of epistemic practices by the students allow the construction of justified knowledge (Motta et al., 2018; Sasseron \& Duschl, 2016; Silva, 2015), we feel that the establishment of a relationship between epistemic practices and the solution of SSI may contribute to the construction of justified positions about the issue. Indeed, Dionor and collaborators (2020), on conducting a research study about teaching proposals based on SSI, highlighted that not always have they opportunised the development of a conscientious position justified by the students. We therefore consider that a better understanding of the role of epistemic practices in approaches of this type could contribute to the field. 
Research studies on epistemic practices within Science Education have been focused on investigative approaches (Motta et al., 2018; Sasseron \& Duschl, 2016; Silva, 2015). One of the main gaps of this specialised literature is the lack of articulations of epistemic practices with the approach based on teaching with SSI. As discussed by Kelly and Licona (2018), there are important differences between the investigative and SSI approaches to teaching, with regard to the goals, types of knowledge used, and the line of reasoning to be developed by the students.

With regard to the purpose of teaching, in the investigative approach it includes the planning and use of results, in seeking to provide an answer to the scientific issue under investigation (Kelly \& Licona, 2018). In the case of the SSI approach, the initial target includes analysis, assessment, discussion of various perspectives about a social issue of scientific ilk, and taking a position with regard to the issue (Sadler, 2009). This is because the solution of an SSI does not only pass through the sphere of Science, either because a consensus has not yet been reached, or because of the many possibilities of answers to the case at hand, for example; for example, based on ethical or moral considerations.

On solving the SSI, the students get involved in a course of reasoning, based on which they analyse and discuss the different slants of the question, so they pay then draw up their own opinions, these being questions with different solutions possible (Sadler, 2009).

In this regard, in relation to the type of knowledge exploited in each of the approaches, in an investigative question it is expected that the students shall collect data, evidence, and explanations of scientific knowledge (Kelly \& Licona, 2018). In contrast, in the case of the SSI approach, the focus is that the students should develop a holistic reasoning with regard to the question. For this reason, the explanations, arguments and evidence shall not be restricted to a merely scientific perspective (Kelly \& Licona, 2018). We are well aware of the fact that, in teaching using an investigative approach, knowledge beyond the scientific sphere could have an influence, or be discussed during the investigation (Franco \& Munford, 2020). However, different from the SSI approach, the discussion of knowledge outside the scientific sphere is not the central goal of the investigative approach.

We therefore consider that the lack of research into epistemic practices in the approach to teaching with QSC could be justified, as a result of the specificities regarding processes of reasoning, objectives, and the knowledge involved in the resolution thereof, bringing in questions like 'how can one research into epistemic practices in contexts of teaching with SSI. The assessment of epistemic practices means an analysis of the types of reasoning regarding knowledge, in terms of the social practices shared by members of a community (Kelly, 2008; Pierson et al., 2019). This having been said, it is notable that two aspects have an influence on the assessment of such practices: the ways of reasoning about knowledge, and the type of community, as well as the methods of interaction that mould the practices involved in the discussion of the problems in the classroom. 
Bearing in mind that the work within a context of teaching with a SSI approach, which are intended to investigate the construction of knowledge, did this in relation to individual reasoning (Sadler, 2004; Sadler \& Zeidler, 2005; Silva, Delmondes et al., 2013; Simonneaux \& Simonneaux, 2009; Zeidler et al., 2009), meaning that, in other words, there was no assessment of this construction in terms of practices, in the present paper we have sought to move on with the relationships between the methods of reasoning about knowledge for the solution of a QSC and the epistemic practices of Science.

We have the support of the perspective of learning from practice communities (Lave, 1992, 1996), as this helps us to envision the classroom regarding it as a community where learning takes place through enculturation and appropriation of the practices as established there (Lave \& Wenger, 1991; Kelly, 2019). It is also important to consider that we are not viewing the classroom as a community with established practice, but consider that this perspective could help us with our thoughts on construction of identity, social practices, and the relationship between learner and teacher in the classroom. In other words, we consider that the perspective of the community of practice favours one looking at the forms by which the interactions in the classroom could mould the practices situated there (Kelly, 2019).

In this regard, bearing in mind that the interactions that occur within these communities are governed by standards, discourse, identities, objectives, and practices shared by its members (Lave, 19920, in the present work we also have the aim of advancing with the particularities of the standards that could be shared in the classroom, using a SSI approach to teaching. This aim is justified due to the work by Sadler (2009) and Kelly and Licona (2018) having exploited the other particularities of this approach; in other words, discourse, identities, goals and practices of the teaching approach using SSI.

The work by Kelly and Licona (2018) had the main purpose of extraction of implications for Science Education, from the empirical research about scientific practices as carried out in the scientific communities. Based on this, the authors defend the view that, depending on the teaching approach used, different aspects of scientific culture shall be emphasised. The authors propose the possibility of conceptual, social, and epistemic aims and epistemic practices as may emerge in different approaches to teaching (investigative, engineering, and SSI).

In the work by Sadler (2009), there was the assessment of empirical research studies with SSI in the classroom, in order to explore the particularities of discourse and identities as identified in this approach.

Therefore, considering the gaps in research studies that i) discuss the particular features of the standards that could be shared by the members of the classroom for the solution of an SSI and ii) establish a link between the ways of reasoning about knowledge for the solution of an SSI and the specialised literature on epistemic practices, in the present work we have the aim of advancing our theoretical relationships. 


\section{Social standards in an approach of teaching with SSI}

The perspective of learning in a community of practice is considered for a study of the classroom culture in which one seeks the appropriation of the students involved in epistemic practices. According to this perspective, the process of learning considers that the cognitive movements of the individual people are derived from their actions and interactions within this environment (Lave, 1992). This means that, as a continuation of the practice, the act of learning lies in certain types of coparticipation between its members. This means that the individual people shall see the meaning of learning as it being a matter of involvement with the practices of the respective communities, from a standpoint of intentional engagement. (González-Howard \& McNeill, 2016). Therefore, a community of practice works around a project, a common goal, while the members mutually engage for the attainment of this goal, and also share a repertoire of common practices to do this (Lave \& Wenger, 1991; Lave, 1992). This means that the objective, the mutual engagement, and the sharing of practices between the members of a community of practice are three elements that we wish to call your attention to, for the social construction of knowledge in the classroom, according to this perspective.

In the case of the approach to teaching with SSI, it is expected that the members of the classroom are organised in a way that shares the common goal of discussion and solution of the SSI (Sadler, 2009). In this article, we defend the view that they shall share, get involved, and appropriate the epistemic practices of Science for the solution of these questions. It is hoped that the students shall have the opportunity to take a position as active contributors with problems of the society, thereby generating interest in the use of their ideas about processes and understandings of Science, in problems that affect society (Sadler, 2009). In this case, the particularity of the community that could be established for the solution of SSI in the classroom lies in the fact that Science is linked to a controversial social problem, for which the students shall take up a position. Based on this perspective, Sadler (2009) discusses that, in the classroom with an SSI approach, it is important that the students develop a feeling of having something to say about the problems; in other words, they should feel part of this problem, participating as if legitimate participants of the social dialogues involved in the discussion.

In this way, aiming at the occurrence of epistemic practices and the involvement of the students in the solution of SSI, then we discussed the standards for interaction, that are relevant for construction in the communities with SSI. The standards that we defend here are connected to those involved in scientific culture, considering the need for enculturation of the students with aspects that have some link to Science. We did this basing ourselves on reference mark about social norms of social knowledge (Longino, 2002; Sasseron \& Nascimento, 2019) and also the work by Zeidler and his collaborators (2009) about reflective judgement in the SSI approach.

On studying the scientific communities, Longino (2002) stresses four types of social norms (moderate equality, public standards for analysis, forum, responsiveness to criticism) which give science greater objectivity, prioritising criticality against the 
statements of knowledge. Nascimento and Sasseron (2019) relate such standards to the social process that may take place within the context of the Science class. They observed that the public standards of analysis and responsiveness to criticism, on being opportunised within a group of students, favoured the construction of explanations that are more and more elaborate, and that have been justified by them. The article by these authors suggests that, when the social norms that guide scientific work also govern the work in the classroom, there is the favouring of the construction of more and more elaborate positions, justified by the students.

Zeidler and collaborators (2009) argue that, in the contexts with SSI, it is important that the teacher show respect and attention to the premises of the students, considering that these are ideas under development and are also genuine and sincere reflections on the way they give a meaning to the world. The authors also highlight the fact that, if the students perceive any disrespect or lack of emotional support, they can show themselves to be less willing to get involved in discussion or to take on the intellectual and personal risks that are necessary for the development of the SSI, and this could block the construction of opinions that are conscientious and justified, about these issues.

This makes us note the importance of construction of moderate equality (Longino, 2002) among the members of the classroom, seeking the creation of an environment where everyone's ideas are respected and taken into consideration at the moment of discussion, setting out from the assumption that everyone has intellectual authority, meaning that they are equally capable of making a contribution, in a more horizontalised relationship of power (Nascimento \& Sasseron, 2019).

We recognise that moderate equality should be prioritised in other approaches to teaching, as allowing moderate equality in the classroom in fact does mean the considerations of the proposals known to the students. However, we wish to call attention to the particularity of the standard of moderate equality in a teaching approach based on SSI. We feel that the teacher, as an epistemic authority, should favour the justification of the students' views about SSI, based on the discussion of the fundamentals of the different perspectives as here invoked, but without having the aim of taking the student to a homogeneous answer. This is different from contexts where the knowledge discussed has already been legitimated by the scientific community, because even if the teacher should consider the different perspectives shown by the students, he or she should guide the discussion to a form of knowledge that has already been legitimated, with the teacher, as an epistemic authority, being the spokesperson representing Science within the school (Stroupe, 2014, 2015; Nascimento \& Sasseron, 2019). To the extent that moderate equality within SSI contexts means considering that different positions with regard to the problem may indeed exist, and that it shall be up to the teacher to support the students in a search for justifications for each of them, so they may gain awareness of the possibilities, and then decide, in a reflective form, about problems that are controversial. 
It is also expected that during the forwarding of the students' positions about the SSI, they would have opportunities to propose and defend their own standpoints regarding the problem and assess the positions that the colleagues have raised (Zeidler et al., 2009). This means it would be important to support the students when appraising data, evidence and arguments put forward about the controversial problem, opportunising that they make appraisal judgements. This makes us realise that, linked to the construction of moderate equality between the members of the classroom, for the consideration of the SVQ solution, there should also be norms connected to what Longino (2002) called public standards and forums. The public standards are those sets of criteria for which the assessments occur critically, thought of like the set of criteria and knowledge that have been presented and/or established with the classroom community. The forums refer to the need for the classroom to be configured as a space for presentation, criticism, and review of evidence, methods, hypotheses, and arguments, among others (Nascimento \& Sasseron, 2019).

With regard to the public standards and forums that could be opportunised in approaches to teaching using SSI, the specificity lies in the fact that the criteria for the assessment of evidence and arguments of each line of reasoning that affects the issue shall have different perspectives. This occurs because, for example, the assessment of moral knowledge involved in SSI must follow the same criteria used for the appraisal of scientific knowledge (Allchin \& Zemplén, 2020; Moshman \& Tarricone, 2016), due to the fact that the former is based on normative principles that guide human actions, while the second is based on evidences (Nunes-Neto \& Conrado, 2021).

Apart from the considerations made by Zeidler et al (2009), we add that the standard regarding responsiveness to criticism (Longino, 2002) must also be opportunised in the approach to teaching with QSC because, considering that different perspectives should exist during the discussion of the controversial problem, the classroom should be configured as a space for presentation, criticism and review of evidence, methods, hypotheses, and arguments, among others, Responsiveness to criticism refers to this process of acceptance of criticism, thoughts, and review of ideas (Longino, 2002; Nascimento \& Sasseron, 2019). In this case, one must consider that, on solving an SSI. There is no 'single' answer (Zeidler, 2015). This means that criticism shall exist in the sense of promoting thoughts about the different feasible possibilities for solving the issue.

Considering the perspective of learning in a community of practice, as we envisage the construction of social norms in the classroom, we are assuming that knowledge and learning are situated within a social practice (Lave, 1992). Social practices, according to Kelly (2008), consist of a standardised set of actions that are recognised by the members of a group with shared purpose, expectations and cultural values. This allows us to understand the imminence of epistemic practices in the SSI approach to teaching because, according to Kelly (2008), epistemic practices are social practices that have a connection with knowledge. 
To understand the particularities of epistemic practices that emerge from reasoning about a SSI, we deepen our studies about reasoning and epistemic cognition (for example, Alexander, 2016; Chinn \& Buckland, 2011; Clément, 2016; Elby et al., 2016; Greene et al., 2016; Kelly, 2016; Kienhues et al., 2016; Kuhn, 1991; Moshman \& Tarricone, 2016; Toulmin, 2006) seeking to understand the fundamental cognitive processes that the students should develop to take up critical positions with regard to the SSI. Later, we identify relationships between reasoning, cognition, and epistemic practices.

Thus, on placing knowledge within a perspective of rationalisation and cognition, we are casting our eyes upon the 'microscopic' dimension of the processes that involve epistemic practices. This having been said, in the following section we shall exploit the relationships that we have established between social norms, social practices, epistemic cognition, reasoning, and epistemic practices, as part of the approach to teaching with SSI.

\section{Epistemic cognition and its connection with social norms and practices}

Setting out from a social and cultural perspective of knowledge, mental processes are internalised based on social interaction (Clément, 2016). Therefore, we defend the view that cognition depends on social factors (Clément, 2016; Kelly, 2008). The term 'cognition' may be used to refer to mental processes (for example, methods of reasoning) and to refer to mental representation (for example, a person's mental representation of a bicycle) (Greene et al., 2016). In this work, we shall be considering the perspective regarding mental processes.

This means that, as knowledge is developed within a community through social interaction, the mental process, like that for justification of a statement, is not merely an individual matter (Clément, 2016). Similarly, in scholastic science, it is desirable that 'what counts' as a contribution for what is considered knowledge should be decided socially - preferably conditional on evidence - rather than being a decision made arbitrarily by an authority (Kelly, 2008). On the other hand, practices learnt by a group are internalised in different ways by individual students (Clément, 2016; Kelly, 2008). In this regard, Kelly (2008) highlights that reasoning has a public and social function, with intersubjective norms and consequences.

Social standards (as highlighted in the previous section) should be opportunised in the approach to teaching based on SSI, seeking to make the epistemic cognition of students be the result of social interactions and favour objectivity of knowledge when solving the questions. Therefore, the key point is that, as Longino (2002) points out, rationalisation and socialisation are both aspects inherent to knowledge, as these are also the social factors responsible for solving scientific controversies, and not only cognitive factors. Therefore, we believe that social factors, just like social norms and practices, and epistemic cognition, should be intertwined so that there may be the solution of the SSI. 
As cognition refers to mental processes, internalised based on the social sphere, and the term 'epistemic' refers to knowledge (this being acquired through social processes), epistemic cognition can be understood as the learnt ways about how to reason, for the construction of knowledge (Elby et al., 2016; Kelly, 2016).

As a result, epistemic cognition shall help with the self-regulation of reasoning (Moshman \& Tarricone, 2016). We therefore understand that epistemic cognition shall involve awareness building, understanding, and internalisation of the individual person, regarding ways of reasoning about knowledge.

Here we should mention that epistemic cognition is also very important for scientific reasoning (Elby et al., 2016; Kuhn, 1982), considering that it involves the generation of hypotheses and assessment of evidence. In this regard, by way of example, we consider that some methods of reasoning about knowledge, which we feel are important to be learnt and should be part of epistemic cognition of students in Science Education are: how to make use of evidence for the construction of statements; how to use practices of reasoning based on models to propose, assess, justify, communicate and legitimate ideas, and so on.

Having said this, we shall go deeper into the reasoning involved in the construction of knowledge, in an approach to teaching based on SSI, seeking to understand the particularities of epistemic cognition.

\section{Epistemic cognition and reasoning in a teaching approach with SSI}

Before we comment on the epistemic cognition that is part of the process for solving SSI. It is worth delving deeper into what we understand as reasoning, and why we have decided on the term 'epistemic cognition'.

Reasoning can be better defined in terms of thought and inference (Moshman \& Tarricone, 2016). In the opinion of the authors, inference normally refers to the generation of new knowledge, using different processes. However, not always do inferences involve the building of awareness in the individual person. This is because initially inference is merely habitual, later becoming conscientious processes (Toulmin, 2006). The building of awareness regarding inference allows people to reflect upon the justifiability of results.

The act of thought involves the control of inferences, involving the regulation thereof (Moshman \& Tarricone, 2016). However, on thinking, people normally tend to adjust their inferences in line with some personal goal. For example, faced with a problem, a person must think of a solution; if the problem is then solved, the thought will have been successful. In this way, thought tends to be more concerned with success than with the awareness of generation of new knowledge or better understanding. For this reason, in daily decisions, when judging or making plans, people tend to coordinate their inferences and develop thoughts to meet their own purposes (Moshman \& Tarricone, 2016).

On the other hand, if the individual person develops a line of thought in order to 
assess what they should believe in, and what shall be considered true ${ }^{1}$, and considers the justifications for different options, then the person is reasoning (Moshman \& Tarricone, 2016), which means that reasoning is related to justification of knowledge (Clément, 2016).

At this moment, it is worth factoring in the counter-argument raised by Alexander (2016), who suggests that people are constantly developing mental processes for thoughts, even when asleep. For this reason, for research purposes, we are assuming that thought involves both awareness and control, and we are also well aware that, as this author believes and defends, in many cases thoughts are spontaneous, rather than being the subproducts of reasoning or rational behaviour.

This means that, for research purposes, we are assuming that, when people regulate their inferential processes in search of justification of their beliefs and opinions, this is considered a process of reasoning. In other words, reasoning refers to forms or aspects of thought that are reflectively directed to justification. In a nutshell, reasoning is a self-regulated process (Moshman \& Tarricone, 2016).

We agree with Moshman and Tarricone (2016) that, in the teaching context it is not enough for the students to make the correct inferences. They must make a reflective coordination of justifications for these inferences based on their epistemic cognition, which means based on some form of reasoning that has been learnt.

In this regard, bearing in mind the purpose of the present article, that of establishing theoretical relationships between different types of reasoning during the solution of an SSI and epistemic practices, instead of worrying about reasoning itself; in other words, the ways of justification of statements of knowledge, we shall be focusing on epistemic cognition, which are the different forms of reasoning. However, before we go into the issue of the epistemic cognition involved in solution of an SSI, we shall be addressing the specificity of the reasoning involved in solution of such questions. In other words, regarding the ways of justifying knowledge during the solution of an SSI.

For the solution of SSI, the students make use of what is known as informal reasoning (Sadler, 2004). This type of reasoning occurs when the problems are open, meaning that the answers are also open and variable, meaning that there is no one single correct answer (Kuhn, 1991). Informal reasoning involves the generation and assessment of different statements, together with justification, to answer complex questions that require solutions or negotiations (Sadler, 2004).

In informal reasoning, one person may make use of formal or informal logic to back up their conclusions. This means that, in order to solve the SSI, the person may guide his or her conclusions based on different perspectives. Logic is concerned with the solidity of the statements we develop - with the grounds we select to back up our conclusions (Toulmin, 2006).

In formal logic, a conclusion is valid when it arises from two valid premises; therefore, if the premises are true, then the conclusion should also be true (Kuhn, 1991;

1 Here it is worth pointing out that Science does not deal with absolute truth, immutable, but deals with possible 'truths', in line with criteria and knowledge as available up to a given moment. 
Moshman \& Tarricone, 2016; Toulmin, 2006).

This, while in informal logic the conclusion is a matter of induction, and guarantees are established based on specific facts that lead (induce) a certain conclusion (Kuhn, 1991; Toulmin, 2006).

This means that, in informal logic, the conclusion is considered true, in the light of three different aspects: 1) the guarantee that supports a statement being true or acceptable; 2) the counterargument (the guarantees in support of the contradiction of the conclusion) and 3) an extension or generalisation in which those guarantees back up a conclusion (Kuhn, 1991).

The difference between formal and informal logic stands in the fact that the former requires a single solution, resulting from a deduction. In contrast, in the latter the answers are more open, as the conclusion results from an induction based on specific facts that establish a conclusion. In the solution of SSI, according to the logic adopted for the construction of conclusions, different ways to justify or guarantee a conclusion shall be called upon. This is because epistemic domains support different types of justifications and evidence (Guimarães et al., 2010; Moshman \& Tarricone, 2016). Therefore, according to the epistemic domain that the subject chooses as guidance for their reasoning about the SSI, there shall always be differences between the ways of solving the SSI.

Therefore, starting out from the principle that epistemic practices shall 'inform' about what counts as relevant knowledge (Kelly, 2008), they can also tell us something about this knowledge, for the positioning of the students during the resolution of an SSI. Based on these practices, one is able to assess which criteria are used to justify a statement (Kelly \& Duschl, 2002; Jiménez \& Crujeiras, 2017). In this way, the epistemic practices during the solution of the QSCs may help the students in assessment of the criteria to justify the statements, according to the epistemic domain involved.

For example, a student could justify the consumption of meat in an SSI on this theme, based on the thematic axis of health, bringing information about the content of protein and fat beneficial to the body, based on scientific evidence. On the other hand, the student could resort to anthropocentric moral considerations to defend this same consumption, as his or her concern would then be essentially with the human being, the source that he or she consumes as food, rather than the animal as a being with intrinsic value (that has a value in itself). Morality is an epistemic domain that involves knowledge of how people should treat themselves. On developing reasoning about moral aspects, one shall consider that moral are more normative than empirical; reasoning based on principles is often a matter of judgement, leading to conclusions with which people may reasonably disagree (Guimarães et al., 2010; Moshman \& Tarricone, 2016).

In the case of moral judgement, considering the difficulties that exist for the establishment of a global consensus regarding values, we agree with the thoughts of Nunes-Neto and Conrado (in press) and Conrado \& Nunes-Neto (2018), when they say that there are criteria that can be considered universal for the establishment of moral rules, which do not depend on perspectives of different cultures, with regard to social 
practices that do not cause (or that minimise) harm and suffering to those people affected by it. In this case, assuming a discussion about the practice of female genital mutilation, common in some countries, a justification to back up the argument of immorality of such a practice could be the fact that this affects and causes harm to women; one possible backup for this could be statements made by different women who have suffered from this practice and have described the feeling of physical pain and mental stress during and after the procedure.

On discussing the differentiations between the epistemic domains and their ways of reasoning and justification of knowledge, we highlight the fact that, during the solution of an SSI, the epistemic practices shall differ according to the area of knowledge being discussed. This is because, according to the epistemic domain, one expects different ways of generation, communication, assessment and legitimation of knowledge.

\section{Epistemic cognition, epistemic practices, and epistemic goals in an approach to teaching with SSI}

In this subsection we mention the epistemic cognition involved in the process of development of a justified position and the solution of an SSI. To start with, we highlight the ideas of Alexander (2016). The author defends the view that cognitive searches that could occur during someone's process of reasoning do not always seek the construction of knowledge. In the opinion of the author, cognitive search could occur based on the management of information and for the construction of knowledge, with epistemic cognition being closer related to the latter case. Information management is an involvement of the individual person, which is guided by the task, using a process of short-term memory. On getting involved in information management, the person has the goal of obtaining the information, but without the need to ensure its veracity or the grounds behind the information that he or she is managing. According to Alexander (2016) this can occur, for example, when the students memorise the content with the intention of getting a good mark in the test, but without the need to ensure veracity of the information they are memorising.

On the other hand, there are some moments when it becomes important to understand the fundamentals of the information and confirm the veracity thereof, as well as just 'obtaining the information'. In this case, the information is linked to personal goals, and the individual people feel some validity in what is being learnt, and try to make it part of their long-term memory (Alexander, 2016). This is the process of construction of knowledge, in which they seek to check the precision or 'veracity' of the information. In this specific case, the goals become epistemic in nature, and the epistemic cognition then shows up (Alexander, 2016). Therefore, in the opinion of this author, epistemic cognition shows up when there is a change in the epistemic goal of the individual, which now starts assessing the precision of the information. Chinn and Buckland (2011) share this idea on stating that cognition shall be epistemic (or not) when we assess the goals that guide it. 
Considering the centrality of epistemic goals, to guide epistemic cognition and, as a result, the epistemic practices of that community, on appraising the ways of reasoning for the construction of knowledge during the solution of SSI, in other words, epistemic cognition as present in this process, we shall link it to epistemic goals that could guide it.

The first aspect that we shall consider with regard to the method of reasoning during the solution of a SVQ refers to the fact that this resolution involves different epistemic domains and different ways of justifying them, and reaching conclusions about them. This means that the first epistemic goal for this approach is, as defended by Kelly and Licona (2018), the understanding of multiple perspectives regarding SSI, for the construction of a coherent line of reasoning which supports a position regarding a controversial issue.

Students should understand that different perspectives or epistemic domains shall be mobilised during the solution of an SSI, This understanding could be important so that the student may realise that different epistemic domains require different methods of justification and to recognise affirmations of knowledge. In this way, in the SSI approach to teaching, it is important that the student understands that what is considered the truth in one epistemic domain shall not follow the same assessment criteria in a different domain.

On considering understanding and use of multiple lines of reasoning, supported by different epistemic domains, as being the first epistemic goal of the SSI approach to teaching, we now present connections between this goal and the scientific context. In Science, scientists also go through processes where it becomes important to judge competitor theories using a wide range of criteria (Kuhn, 1982). In other words, they make use of informal logic on considering multiple theories and make conclusions about them. In the same way that scientists use informal logic to gain insights into the natural world, students should use it on making enlightened decisions about the controversial problems they face.

In this regard, we consider that epistemic cognition, when solving SSI, should include an assessment of the explanations, according to the field of knowledge. It is therefore expected that the students develop epistemic cognition that proposes to develop criteria for the appraisal of arguments and justifications that are plausible within each epistemic domain. In the case of the SSI approach to teaching, these criteria involve a search for justifications for believing in a certain view of the problem. Such criteria may help the students to move away from emotional and intuitive decisions, as it is expected that they take up justified positions and that they develop means to make conscientious decisions within an QSC (Zeidler, 2015).

We feel that, for the student to be able to look into the different perspectives of the SSI, it is important that he or she gets involved in consultation processes, just like scientists do, which includes making questions (problems), proposing hypotheses, comparing theories and alternative models, and so on (Irzik \& Nola, 2014; Sadler et al., 2017) 
The scientific community carries out an assessment of the evidence, according to the specific types of problems to be solved, governed by normative criteria established by the communities (Osborne, 2014). In this way, we expect the students to know how to appraise evidence and justification according to normative criteria of the different domains. In other words, the students should learn how to analyse and appraise data, statements and arguments, in a variety of representations, and reach appropriate conclusions according to the epistemic domain that has been assessed (Alchin \& Zéplem, 2020). This having been said, we stress the particularity of the process for evidence assessment within the context of the SSI as, these questions being of a social ilk, it is important that the students pay attention to cognitive trends motivated by ideologies, as in some cases the 'motivated reasoning' distorts the conscientious appraisal of arguments (Allchin \& Zemplén, 2020), which can jeopardise the main goal of SSI, that of getting the students to take up conscientious and justifiable positions.

Another aspect of epistemic cognition that needs to be considered when the students are dealing with SSI is the recognition of the complexity of knowledge, and its relation with the available information (Kienhues et al., 2016). This is coherent with the ideas of Sadler, Barab e Scott (2007), as these authors, on defining processes of reasoning based on the solution of SSI (a construct known as socioscientific reasoning), defend the viewpoint that the students should develop their ability to perceive and recognise the inherent complexity of SSI. This makes us understand that, apart from the appraisal of arguments according to the epistemic domain, as previously mentioned, the construction and assessment of holistic arguments, seeking to consider the multiple dimensions that affect the SSI, is the second epistemic domain that needs to be taken into account for this approach.

Argumentation in Science Education enables the choice of theories based on an analysis of alternative explanations in terms of consistency with available evidence (Duschl, 2008a; Osborne, 2014). It allows students to understand just why one theory is more coherent than another, instead of just accepting this fact. This is because argumentation requires the development of statements based on justifications (Duschl, 2008a). In this way, when we consider the epistemic goals behind the construction and assessment of holistic arguments by students, we want to say that they should be capable of accessing, understanding, analysing, assessing, comparing, and contrasting information from a variety of sources, as well as using them carefully for the synthesis of their own decisions about SQC, based on arguments which take into account the different dimensions that affect the issue. Thus, the specificity of arguments made during the solution of these issues lies in the fact that students need to associate knowledge from different epistemic domains to construct such arguments. This suggests that different types of justifications and evidence need to be linked so that arguments may be constructed.

Kelly and Licona (2018) suggest that one of the epistemic practices as present in an approach to teaching with SSI refers to the development of an investigation, in 
order to answer questions. On accepting the importance of students acknowledging the complexity of such issues, we add that this aspect should be taken into account, so that the investigation may press on, based on normative criteria.

In the case of investigation into SSI, we consider that the students may generate hypotheses regarding the problem as proposed, appraise hypotheses based on an analysis and assessment of different pieces of information about this, select the information they consider important for the development of a personal opinion.

In addition, it is important that the development of epistemic cognition follows the direction shown by Sadler et al. (2007), that of favouring the students' development of the ability to recognise that some information is not available with regard to SSI, and also the ability to consider ways in which this information may be generated, accepting the fact that the SSI is subject to ongoing investigation.

Together with this, we consider that the students should develop their epistemic cognition, seeking to identify the sources of the information, bearing in mind that they could have an influence upon the information regarding a problem or solutions. This makes it important for the students to show some scepticism when they are presented with information that could be potentially biased (Sadler et al., 2007). As according to the views of Chinn and Buckland (2011), there are some virtues that, on being interconnected with epistemic cognition, help with the attainment of the epistemic objectives, as is the case of the virtue of having an open mind.

Irzik and Nola (2014) highlight that scepticism and an open mind are values of the scientific community, as scientists subject all statements to a logical and empirical examination based on clearly specific procedures involving scientific reasoning, suspending the judgement until all the relevant facts are selected and not bowing to any authority, except in making critical argumentation.

This having been said, we feel that the development of sceptical investigation, which considers different sources of information regarding SSI, is the third epistemic goal that se envisage for the construction of knowledge and a critical position within the SSI approach. It is also worth observing, as defended by Sadler et al. (2007), that the investigation of a SSI should consider that the knowledge under investigation is still being discussed, meaning that these are investigations on matters that are still open. This is a specificity of investigation as developed in the SSI approach to teaching, suggesting that the students should be aware that the solution of this investigation shall be up to the student himself or herself, and that it shall be the student who shall take up a final position about the issue that is being investigated, as there is no legitimate knowledge for this purpose. Here, it is important to state that, within the scholastic context of Science Education, one would expect this to be an enlightened position. Therefore, we believe that the development of a position should be worked on, setting out from the epistemic goals of the SSI approach to teaching and from the epistemic practices derived therefrom, seeking the creation of a teaching environment where priority is given to the objectivity of the knowledge discussed based on the process of rationalisation and social norms for interaction. 


\section{A model for relationships between epistemic practices and the SSI approach in Science Teaching}

We have developed a model, shown in Figure 1, seeking to make a representation of the relations we have established so far, with regard to reasoning, cognition, practice, and epistemic goals within the development of epistemic practices in the SSI approach. It is important to mention that, in this work, we do not make any efforts to project types of epistemic practices that arise in the SSI context, as we consider the contextual character of these (Kelly, 2008, 2016), we believe that it is the epistemic goals that should be given priority, so that the practices may emerge.

Figure 1. A Model that Addresses Relations between Sporting Practices and SSI in Science Education

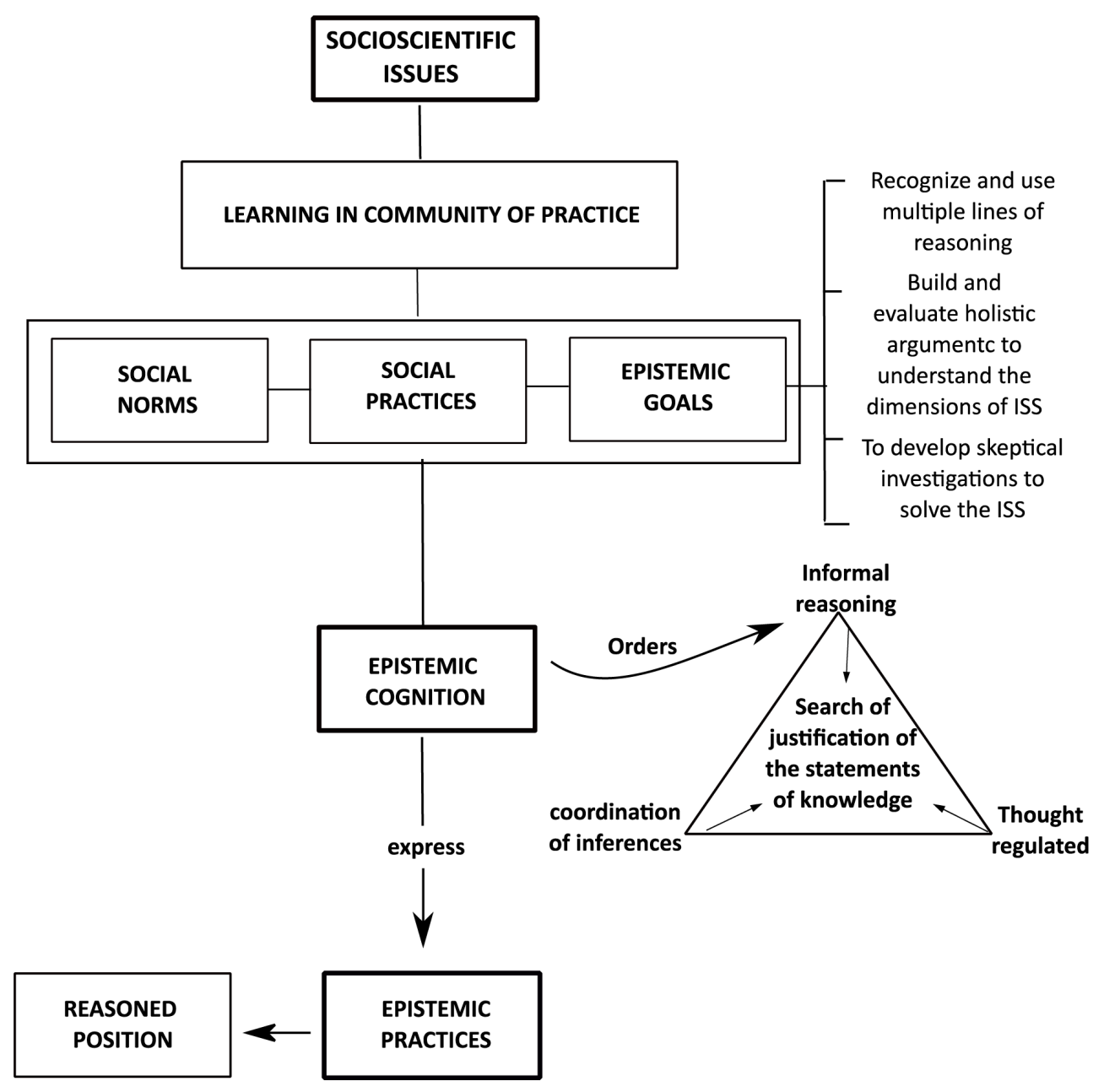

In this model (shown in Figure 1 above), we show the socioscientific questions at the top, showing that interactions in the classroom occur based on discussions and their solutions. In this way, we expect that the core goal, shared between the members of the science classroom, is that of solution of the SSI. Considering the perspective of a 
community of practice, we expect, as shown in the line that connects the SSI with the perspective of community of practice, that the resolution of these questions may occur based on work based on norms, practices and goals shared between students and teacher (Pierson et al., 2019; Stroupe, 2015), so that it may be possible for epistemic practices to emerge and be assessed. Therefore we inform, based on lines of connection between the rectangles showing practices, norms, and goals, that they are aspects inherent to the culture of a community (Lave, 1992).

Looking towards the target of Science Education, that of approximating the culture of the classroom with the scientific culture and also offer work with the epistemic goals of Science ( Jiménez-Aleixandre \& Crujeiras, 2017; Kelly \& Licona, 2018), we suggest the types of goals and standards that are expected to be opportunised in the classroom, so that its members may work in terms of a community. We defend that the social standards highlighted by Longino (2002) within the scientific context - moderate equality, public norms for analysis, forum, and responsiveness to criticism - should be constructed in the classroom, taking into consideration the particularities of the approach to teaching with SSI.

The epistemic goals as shown in Figure 1 show that the students should 1) recognise and use multiple lines of reasoning on solving SSI, in a perspective that allows them to know how to assess evidence and justifications, based on normative criteria for each kind of reasoning; 2) construct and appraise holistic arguments which consider the different domains that affect SSI, considering their complexity, and 3) develop sceptical investigations to solve the SSI.

In Figure 1, the rectangle that includes the norms for social interaction, social practices, and epistemic goals, is connected to the rectangle for epistemic cognition. We have indicated this connection, as it is the epistemic goals that guide cognition (Alexander, 2016; Chinn \& Buckland, 2011) and, as a result, shall also guide the epistemic practices that shall be a part of this community (Berland et al., 2015; JiménezAleixandre \& Crujeiras, 2017), as cognition is expressed based on practices (Kelly, 2016), as shown by the arrow connecting them. At the same time, the connection between social practices and social norms with epistemic cognition is justified because it is expected that knowledge involved in the solution of the SSI shall be promoted by means of social interaction. Therefore, the methods of reasoning that we expect the members of this community to internalise are the result of public reasoning guided by social norms and practices.

As shown by the arrow, epistemic cognition should regulate the processes of reasoning, or in other words, the ways of justifying knowledge. It is expected that the students co-ordinate, in a reflective manner, their inferences based on their epistemic cognition (Moshman \& Tarricone, 2016). As the QSCs require appraisal of different perspectives regarding the issue at hand (Sadler, 2004), different epistemic domains shall be considered in the discussion. As a result, the ways of justification of knowledge shall also be different (Guimarães et al., 2010; Moshman \& Tarricone, 2016). 
Informal reasoning guides the process for resolution of SSI, as this is required in the analysis of complex or controversial issues, in the justification of the statements and consideration of the arguments (Sadler, 2004). The arrow that shows informal reasoning connected to the triangle (Figure 1) shows that this type of reasoning requires a search for justification of knowledge (Kuhn, 1982), in which thought shall be regulated, and inferences shall be co-ordinated by this search. This is because reasoning implies a conscientious regulation of thought and reflective co-ordination of inferences (Moshman \& Tarricone, 2016).

Epistemic cognition was the link that allowed us to connect reasoning to epistemic practices, as this cognition regulates reasoning and is shown based on practices. Therefore, reasoning (in other words, the ways of justifying knowledge) that shall be shown based on epistemic practices shall follow the cognitive criteria about how to reason about knowledge (epistemic cognition), as agreed by members of a community.

Here it is worth stressing what we consider as valid knowledge within the discussion of socioscientific questions. The criteria would be: knowledge is contextual, passing through processes of rationalisation and socialisation, these being criteria that grant objectivity thereto.

Cultural psychology (Lave, 1992) shows that specific propositions or procedures are only considered knowledge regarding interactions between individual people in specific contexts. By way of example, in some contexts, the concept of evolution is considered as knowledge as it is useful and has been legitimated. In others, the opposite happens. In this later concept, a deep understanding of evolution is neither useful nor normative and, therefore, from a contextualised point of view, it is not appropriate to refer to evolution as 'knowledge'. (Greene et al., 2016). Therefore, the status of a proposition as knowledge, and its 'sophistication', also depend on the context in which they are being assessed (Sandoval, 2005). Thus, the epistemic practices developed within the communities shall inform what is considered knowledge within that context (Kelly, 2008). Therefore, whatever counts as moral, economic, political and scientific knowledge, valid for solution of SSI, shall be subject to assessment by communities, based on the epistemic practices that emerge.

With regard to the rational characteristic, knowledge is different from an opinion, mainly due to the rational bias as involved in the former (Greene et al., 2016). Therefore, what is considered knowledge must involve justification, regulated thought, and coordination of inferences. In this way, knowledge involved in epistemic practices require rationalisation. This aspect is shown in Figure 1 through the arrow connecting reasoning with epistemic cognition.

In this regard, we feel that the involvement of students in epistemic practices during the solution of SSI opportunises the rational assessment of such issues and the development of a justified opinion position, as shown by the connection between the rectangle of epistemic practices, and that of justified position, as shown in the model. 


\section{Final comments}

The purposes of this paper were (i) to discuss the particularities of the norms and standards that can be shared by the members of the classroom for solving an SSI, and (ii) establish a relationship between the ways of reasoning about knowledge to solve an SSI and the specialised literature on epistemic practices.

Regarding the first purpose, we consider that, as epistemic practices are also social (Kelly, 2008), space shall be given for the explanation of public reasoning guided by social norms, so that both may make knowledge more objective (as opposed to subjective). Together with this, in view of the need for approximation of the classroom culture with scientific culture, we suggest that social norms such as those observed by Longino (2002) within the scientific community (moderate equality, public norms, responsiveness to criticism) are important for opportunisation in the classroom, through an approach to teaching based on SSI.

Moderate equality, opportunised as part of the approach to teaching with SSI, should take into account that all members of the community shall be equally able to propose perspectives to solve the issue, and take positions regarding the issue, and the teacher shall have to guide the students to seek grounds for their ideas. In cases with opportunisation of public standards and forums for appraisal and criticism of the perspectives, one must look into the particularity of the criteria for analysis of evidence and arguments for each perspective affecting the question. For responsiveness to criticism, one must consider that, in the context for solution of a SSI, there is not one 'single' answer (Zeidler, 2015), meaning that criticism should exist in a sense of promoting thought about different feasible possibilities to solve the issue, but not to direct towards a more legitimate form of knowledge.

Regarding the second purpose of this article, on deepening our study of concepts of reasoning and the processes involved in ways of reasoning, we see that reasoning is linked to the ways of justifying knowledge (Alexander, 2016; Moshman \& Tarricone, 2016) and cognition is also tied to the ways of reasoning about knowledge (Chinn \& Buckland, 2011; Clément, 2016; Kelly, 2016). Based on this, we turn our eye to epistemic cognition, as involved in the process for solution of an SSI and try to link this cognition with epistemic practices.

We suggest that epistemic cognition is the link between reasoning and epistemic practices, because epistemic cognition is accessed based on epistemic practices, and this cognition refers to learnt types of reasoning about knowledge (Kelly, 2016). Hence, epistemic practices refer to ways of reasoning about knowledge picked up in communities. Bearing in mind the gap in research in Science Education that link reasoning and epistemic practices, we consider that this is one of the main advances made by our paper. Even though Kelly (2016) has indeed proposed important relationships on epistemic cognition and epistemic practices, this author has not made any comments about reasoning, epistemic practice, and epistemic goals, as has been done in this paper.

Due to the nature of SSI, their solution can be led from different perspectives 
- such as those based on the well-being of society and human empathy, on economic aspects involved in the issue, or supported by scientific content (Sadler, 2007). Each new perspective may be guided by a different justification (Moshman \& Tarricone, 2016).

Based on this, we note that the first aspect we should consider, with regard to the epistemic cognition involved in solution of a SSI, refers to the fact that this solution involves different epistemic domains and different ways of justifying them and reaching conclusions about them. Considering also that epistemic cognition is guided by epistemic goals (Alexander, 2016; Chinn \& Buckland, 2011), this shows that, as defended by Kelly and Licona (2018), one epistemic objective that should guide the appearance of epistemic practices in contexts of SSI teaching refers to: allowing the students to recognise different perspectives and use multiple lines of reasoning, when solving the question.

On going deeper into our study of epistemic cognition involved in solution of an SSI, we consider that, when people deal with controversial problems, it is important that their cognition should include the appraisal of the complexity of the problem, and the knowledge involved, based on the creation of strategies such as construction of holistic arguments to think about the problems. Together with this complexity of the SSI, we consider it important, for epistemic cognition, that there be understanding of the influences of information sources, seeking to assess when they show themselves to be potentially biased (Sadler et al., 2007).

On considering these aspects that should be part of epistemic cognition for critical and justified solution of an SSI, this enabled the proposal of two more epistemic goals that should be given priority in an approach to teaching with SSI, so epistemic practices may emerge. This means we include two more epistemic goals apart from what has been shown in the work by Kelly and Licona (2018). The former refers to: construction and assessment of holistic arguments, seeking to understand and consider the multiple dimensions of SSI. So that students may accept the complexity of the problem involved in SSI and come up with arguments based on multiple sources and readings of the different domains affecting the issue. The specificity of arguments about an SSI is in the fact that students need to link knowledge of different epistemic domains in order to construct them. The second refers to development of sceptical investigations to look into the different perspectives that affect SSI in the search for critical and justified positions, so that students may see that some information regarding SSI is not available, accepting that SSI is subject to ongoing investigations, and so develop scepticism so that they may make all appraisals rationally, suspending any judgement until all relevant facts have been selected, and do not subject oneself to any authority, except when making critical argumentation. Here it is worth pointing out that the specificity involved in solving an SSI lies in the fact that the knowledge investigated is still under discussion, meaning that these are investigations of issues that are still open (Sadler, 2007).

We stress that the deepening of our study of epistemic cognition and epistemic goals (Alexander, 2016; Chinn \& Buckland, 2011; Clément, 2016; Greene et al., 2016) made us realise that, in order to research about reasoning in teaching situations, it is 
important that researchers pay attention to which goals the students attach themselves to in these situations, as also why they take up these goals (or, in other words, what are the beliefs behind such goals) (Chinn \& Buckland, 2011). Therefore, we believe that research studies that appraise epistemic goals (about if and why students adopt them) which we have identified in our study are indeed relevant.

We consider that the interlinkings and notes that have been made in this article do indeed collaborate towards research that seeks to develop and analyse epistemic practices in SSI contexts, as they establish detailed relationships between cognitive processes involved in the solution of these questions and those that occur within scientific activities.

In addition, on expanding the epistemic goals of the approach of teaching with SSI we offer new means to achieve the prior conditions set for scientific literacy (Hodson, 2018) for Science Education, as they have the potential to contribute for the assessment and critical solution of SSI, as for the development of epistemic cognition by the students.

We consider that the points raised in this manuscript also help to support the work of teachers seeking to favour epistemic practices in teaching contexts with an SSI approach, as we consider that the teacher can surpass the epistemic goals highlighted in our work, in their classroom activities, allowing the students to be aware of the purpose of the their actions, as from the direction thereof. We have shared the ideas of Berland et al. (2015) that, on organising activities in the classroom with regard to these goals, the students shall be involved in work with aspects of epistemology of Science, within a perspective that allows them to understand and recognise the type of goal that their community in the classroom shall work on.

Last but not least, given the innovative character of the relationships established herein, we consider the importance of the fact that empirical studies shall be carried out, in order to assess the scope and limitations of the model as here presented. It is also worth pointing out that this goal has been the result of an investigation by the authors of this work and some collaborators.

\section{Thanks}

We would like to thank the Coordination for the Improvement of Higher Education Personnel (CAPES) (financing code 001) and the Graduate Studies Programme in Education of the Federal University of Ouro Preto (UFOP) for the financing and the grant that have made this research study possible.

\section{References}

Alexander, P. A. (2016). The Arguments for and the Reasoning About Epistemic Cognition. In J. A. Greene, W. A. Sandoval, \& I. Braten (Eds.), Handbook of Epistemic Cognition, 100-110. New York: Routledge.

Allchin, D., \& Zemplén, G. A. (2020). Finding the place of argumentation in science education: Epistemics and Whole Science. Science Education, 104(5), 907-933. https:// doi.org/10.1002/sce.21589 
Berland, L. K., Schwarz, C. V., Krist, C., Kenyon, L., Lo, A. S., \& Reiser, B. J. (2015). Epistemologies in Practice: Making Scienti ${ }^{\oplus} \mathrm{c}$ Practices Meaningful for Students. Journal of Research in Science Teaching, 53(7), 1-31. https://doi.org/10.1002/tea.21257.

Chinn, C. A., \& Buckland, L. A. (2011). Expanding the Dimensions of Epistemic Cognition: Arguments From Philosophy and Psychology. Educational Psychologist, 46(3), 141-167. https://doi.org/10.1080/00461520.2011.587722

Christodoulou, A., \& Osborne, J. (2014). The Science Classroomas a Site of EpistemicTalk: ACase Study of aTeacher's Attempts toTeach Science Based on Argument. Journal of Research in Science Teaching, 51(10), 1275-1300. https://doi.org/10.1002/tea.21166

Clément, P. (2016). Social Cognition. In J. A. Greene, W. A. Sandoval, \& I. Braten (Eds.), Handbook of Epistemic Cognition, 86-99. Routledge.

Conrado, D. M., \& Nunes-Neto, N. (2018). Questões Sociocientíficas e Dimensões Conceituais, Procedimentais e Atitudinais dos Conteúdos no Ensino de Ciências. In D. M. N. Conrado, N. N. (Ed.), Questões Sociocientíficas: fundamentos, propostas de ensino e perspectivas para ações sociopolíticas, 77-120. Salvador: Editora da Universidade Federal da Bahia.

Dionor, G. A., Conrado, D. M., Martins, L., \& Neto, N. N. (2020). Avaliando Propostas de Ensino Baseadas em Questões Sociocientíficas: Reflexões e Perspectivas para Ciências no Ensino Fundamental. Revista Brasileira de Pesquisa em Educação em Ciências, 20(u), 429-464. https://doi.org/10.28976/1984-2686rbpec2020u429464

Duschl, R. (2008). Science Education in Three-Part Harmony: Balancing Conceptual, Epistemic, and Social Learning Goals Review of Research in Education, 32(1), 268-291. https://doi.org/10.3102/0091732X07309371

Duschl, R. (2008a) Quality argumentation and epistemic criteria. In: Erduran. S.; Jiménez-Aleixandre, M. P. (Ed.). Argumentation in science education: perspectives from classroom-based research. Dordrecht: Springer, 159-178. https://doi.org/10.1007/978-14020-6670-2_8

Elby, A., Macrander, C., \& David, H. (2016). Epistemic Cognition in Science. In J. A. Greene, W. A. Sandoval, \& I. Braten (Eds.), Handbook of Epistemic Cognition 113-127. Routledge.

Franco, L., \& Munford, D. (2020). Aprendizagem de ciências: uma análise de interações discursivas e diferentes dimensões espaço-temporais no cotidiano da sala de aula. Revista Brasileira de Educação, 25, 1-31. https://doi.org/10.1590/s1413-24782020250015

González-Howard, M., \& McNeill, K. L. (2016). Learning in a Communityof Practice: Factors Impacting English-Learning Students' Engagement in Scientific Argumentation. Journal of Research in Science Teaching, 53(4), 527-553.https://doi.org/10.1002/tea.21310

González-Howard, M., \& McNeill, K. L. (2019). Teachers' framing of argumentation goals: Working together to develop individual versus communal understanding. Journal of Research in Science Teaching, 56(6), 1-24. https://doi.org/10.1002/tea.21530 
Greene, J. A., Sandoval, W. A., \& Braten, I. (2016). An Introduction to Epistemic Cognition. In J. A. Greene, W. A. Sandoval, \& I. Braten (Eds.), Handbook of Epistemic Cognition, 1-16. Routledge.

Guimarães, M. A., Carvalho, W. L., \& Oliveira, M. S. (2010). Raciocínio Moral na Tomada de Decisões em Relação a Questões Sociocientíficas: O Exemplo do Melhoramento Genético Humano. Ciência \& Educação, 16(2), 465-477. https://doi.org/10.1590/S151673132010000200013

Hodson, D. (2018). Questões Sociocientíficas: Fundamentos, Propostas de Ensino e Perspectivas para Ações Sociopolíticas. In D. M. Conrado \& N. N. Neto (Eds.), Realçando o Papel da Ética e da Política na Educação Científica: Algumas Considerações Teóricas e Práticas sobre Questões Sociocientíficas. Salvador: Editora da Universidade Federal da Bahia.

Irzik, G., \& Nola, R. (2014). International handbook of research in history, philosophy and science teaching New directions for nature of science research, 999-1021. Springer.

Jiménez-Aleixandre, M., \& Crujeiras, B. (2017). Epistemic pratices and scientific practices in science education. Science Education, 31, 69-89. https://doi.org/10.1007/978-946300-749-8_5

Kelly, G. (2008). Inquiry, activity and epistemic practice. In R. Duschl \& R. E. Grandy (Eds.), Teaching Scientific Inquiry: recommendations for research and implementation, 288-291. Taipei Sense Publishers.

Kelly, G. (2016). Methodological Considerations for the Study of Epistemic Cognition in Practice. In J. A. S. Greene, W. A. Braten, I. (Ed.), Handbook of Epistemic Cognition, 393-408. Routledge.

Kelly, G., \& Duschl, R. (2002). Toward a research agenda for epistemological studies in science education. Paper presented at the Annual meeting of the National Association for Research in Science Teaching, New Orleans, LA.

Kelly, G., \& Licona, P. (2018). Epistemic Practices and Science Education. In M. R. Matthews (Ed.), History, Philosophy and Science Teaching, 139-165. Springer.

Kienhues, D., Ferguson, L., \& Stahl, E. (2016). Diverging information and epistemic change. In J. A. Greene, W. A. Sandoval, \& I. Braten (Eds.), Handbook of epistemic cognition, 318-330. Routledge.

Kuhn, D. (1982). Connecting Scientific and Informal Reasoning. JSTOR, 39(1), 74-103. http://www.jstor.org/stable/23087301

Kuhn, D. (1991). The Skills of Argument. New York: Cambridge University. https://doi.org/10.1017/CBO9780511571350

Lave, J. (1992). Learning as Participation in Communities of Practice. Paper presented at the Annual Meeting of the American Educational Research Association San Francisco, California. 
Lave, J. (1996). Teaching, as learning, in practice. Mind, culture, and activity, 3(3), 149164. https://doi.org/10.1207/s15327884mca0303_2

Lidar, M., Lundqvist, E., \& Ostman, L. (2005). Teaching and Learning in the Science Classroom: The Interplay Between Teachers' Epistemological Moves and Students' Practical Epistemology. Wiley InterScience, 149-163.

Longino, H. (2002). The Fate of Knowledge. Princeton University Press. http://www.jstor. org/stable/j.ctv2tvzv0

Mendonça, P. C. C. (2020). De que Conhecimento sobre Natureza da Ciência Estamos Falando?. Ciência \& Educação, 26, 1-16. https://doi.org/10.1590/1516-731320200003.

Moshman, D., \& Tarricone, P. (2016). Logical and Causal Reasoning. In J. A. Greene, W. A. Sandoval, \& I. Braten (Eds.), Handbook of Epistemic Cognition, 54-67. Routledge.

Motta, A. E., Medeiros, M. D., \& Motokane, M. T. (2018). Práticas e movimentos epistêmicos na análise dos resultados de uma atividade prática experimental. Alexandria: Revista de Educação em Ciência e Tecnologia, 11,337-359. https://doi.org/10.5007/1982$5153.2018 \mathrm{v} 11 \mathrm{n} 2 \mathrm{p} 337$

Nascimento, L. A., \& Sasseron, L. H. (2019). A constituição de normas e práticas culturais nas aulas de ciências: proposição e aplicação de uma ferramenta de análise. Revista Ensaio Pesquisa em Educação em Ciências, 21, 1-22. https://doi.org/10.1590/198321172019210104

Nunes-Neto, N. N., \& Conrado, D. M. (2021). Ensinando ética. Educação em revista, 27, 1-28. https://doi.org/10.1590/0102-469824578

Osborne, J. (2014). Handbook of Research on Science Education. In N. G. Lederman \& S. K. Abell (Eds.), Scientific Practices and Inquiry in the Science Classroom Vol. II, 593-613. Routledge.

Pierson, A. E., Clark, D. B., \& Kelly, G. (2019). Learning Progressions and Science Practices: Tensions in Prioritizing Content, Epistemic Practices, and Social Dimensions of Learning. Science \& Education. 28, 833-831. https://doi.org/10.1007/s11191-01900070-0

Sadler, T. D. (2004). Informal Reasoning Regarding Socioscientific Issues: A Critical Review of Research. Journal of Research in Science Teaching, 41(5), 513-536. https://doi. org/10.1002/tea.20009

Sadler, T. D. (2009). Situated learning in science education: socio-scientific issues as contexts for practice. Studies in Science Education, 45(1), 1-42. https://doi. org/10.1080/03057260802681839

Sadler, T. D., Barab, S. A., \& Scott, B. (2007). What Do Students Gain by Engaging in Socioscientific Inquiry? Research Science Education, 37, 371-391. https://doi. org/10.1007/s11165-006-9030-9 
Sadler, T.D., Foulk, J.A., \& Friedrichsen, P.J. (2017). Evolution of a model for socioscientific issue teaching and learning. International Journal of Education in Mathematics, Science and Technology, 5(2).

Sadler, T. D., \& Zeidler, D. L. (2005). Patterns of informal reasoning in the context of socioscientific decision-making. Journal of Research in Science Teaching, 42(1), 112-138. https://doi.org/10.1002/tea.20042

Sandoval, W. A. (2005). Understanding Student's Pratical Epistemolgies and Their Influence on Learning Through Inquiry. Science Education, 89(4), 634-656. https://doi. org/10.1002/sce.20065

Sasseron, L. H., \& Duschl, R. (2016). Ensino de Ciências e as Práticas Epistêmicas: O papel do professor e o engajamento dos estudantes. Investigações em Ensino de Ciências, 21(2), 52-67. http://dx.doi.org/10.22600/1518-8795.ienci2016v21n2p52

Silva, A. C. (2015). Interações Discursivas e Práticas Epistêmicas em Sala de Aula de Ciências. Revista Ensaio Pesquisa em Educação em Ciências, 17, 69-96. http://dx.doi. org/10.1590/1983-2117201517s05

Silva, K. M., Delmondes, A. V., Silva, S. M., \& Santos, W. L. (2013). Questões sociocientíficas: uma análise do Raciocínio Informal a partir de discussões sobre aquecimento global. Artigo apresentado em IX Encontro Nacional de Pesquisa em Educação em Ciências, Águas de Lindóia, SP.

Simonneaux, L., \& Simonneaux, J. (2009). Students' socio-scientific reasoning on controversies from the viewpoint of education for sustainable development. Cultural studies of science Education, 4(3), 657-687. https://doi.org/10.1007/s11422-008-9141-X

Stroupe, D. (2014). Examining Classroom Science Practice Communities: How Teachers and Students Negotiate Epistemic Agency and Learn Science-as-Practice. Science Education, 98(3), 487-516. https://doi.org/10.1002/sce.21112

Stroupe, D. (2015). Describing "Science Practice" in Learning Settings. Science Education, 99(6), 1033-1040. https://doi.org/10.1002/sce.21191

Toulmin, S. (2006). Os usos do argumento (2. ed.). Martins Fontes.

Zeidler, D. L. (2015). Socioscientific Issues as a Curriculum Emphasis. In N. G. A. Lederman, S. K. (Ed.), Research on Science Education. Vol. II, 697-726: Routledge.

Zeidler, D. L., Herman, B. C., \& Sadler, T. D. (2019). New directions in socioscientific issues research. Disciplinary and Interdisciplinary Science Education Research, 1(11), 2-9. https://doi.org/10.1186/s43031-019-0008-7

Zeidler, D. L., Sadler, T. D., Applebaum, S., \& Callahan, B. E. (2009). Advancing Reflective Judgment through Socioscientific Issues. Journal of Research in Science Teaching, 46(1), 74-101. https://doi.org/10.1002/tea.20281 
Zeidler, D. L., Sadler, T. D., \& Howes, M. L. (2005). Beyond STS: A Research-Based Framework for Socioscientific Issues Education. Wiley Periodicals, 358-376. https://doi. org/10.1002/sce.20048

\author{
${ }^{\oplus}$ Tatiana Costa Ramos \\ Federal University of Ouro Preto (UFOP) \\ Ouro Preto, Minas Gerais, Brazil \\ tatianaquimica@outlook.com \\ ${ }^{-1}$ Paula Cristina Cardoso Mendonça \\ Universidade Federal de Ouro Preto (UFOP) \\ Ouro Preto, Minas Gerais, Brazil \\ paulamendonca@ufop.edu.br
}

Editor in charge

Maíra Batistoni e Silva

Disclosure statement

No potential conflict of interest was reported by the authors.

Compliance with Ethical Standards

The authors declare this study was conducted following ethical principles. 